\title{
Realigning Economic Development to Support Company Startup and Scale Up: A Burlington, Ontario Case Study
}

\begin{abstract}
Anita Cassidy, B.Sc., M.Sc. M.A.
In 2015 the City of Burlington developed a new 2015-2040 Strategic Plan: Grow Bold, which tasked Burlington Economic Development Corporation (BEDC) with supporting the start up and scale up of companies and making Burlington a start up destination. This article will outline the process that BEDC went through to better understand the local innovation ecosystem and the role that BEDC could play in supporting it. This process resulted in BEDC going from no role in supporting companies to start and grow to launching, TechPlace, Burlington's new innovation Centre in 2017, which supported over 4,000 visitors in their entrepreneurial journey in year one of operations.
\end{abstract}

Keywords: Innovation, Entrepreneurship, Startups, Job Creation, Startup Support, Innovation Centre

\section{Introduction}

In 2015 the City of Burlington developed a new 2015-2040 Strategic Plan: Grow Bold, which added a new economic focus for Burlington to become one of the top communities in Canada to start and grow a business. This strategy tasked Burlington Economic Development Corporation (BEDC), an organization traditionally focused on attracting and retaining mid to large sized companies, with developing a strategy focused on supporting small business and entrepreneurship in Burlington. BEDC operated in a two tier municipal environment with the upper tier, Halton Region, managing small business services and had virtually no experience in supporting the startup and scale up of companies. This paper will outline BEDC's process to create a strategy that understands the economic drivers for entrepreneurship, which included best practice analysis by successful entrepreneurship ecosystems and local stakeholder engagement, that helped determine the role BEDC could play in positioning Burlington as a startup hub.

BEDC undertook an extensive process involving stakeholder engagement and research to assess and understand the drivers and impacts of innovation and entrepreneurship. This included reviewing the different types of entrepreneurship, the resources available to support them locally and the gaps that BEDC could help fill. A key gap identified locally, provincially and nationally was the support available to help companies 'scale up'. In 2016 BEDC finalized its Innovation and Entrepreneurship Strategy which outlined a robust Innovation and Entrepreneurship ecosystem in the region with the need for stronger coordination and connectivity amongst organizations supporting entrepreneurs. The clear recommendation of the strategy was to 
develop an Innovation Centre in Burlington that brought all the resources to serve entrepreneurs under one roof in a 'one stop shop' and to provide space, mentorship and robust programming for companies looking to scale up.

This strategy was presented to the BEDC board in October 2016 and approval given to launch an Innovation Centre. By June of 2017 Burlington's new innovation Centre 'TechPlace' was launched which brought key startup resources for entrepreneurs and scaling companies under one roof including:

- HalTech Regional Innovation Centre

- Angel One Investor Network

- Service Provider Office Hours

- LaunchPad spaces to support scaling companies

- Event, Meeting and Hot Desking space

By the end of 2017 BEDC had gone from an organization that had no strategy on Innovation and Entrepreneurship to launching TechPlace a community hub providing a 'one stop destination' with key resources to support companies in starting-up and scaling up.

\section{Background}

The new Burlington Strategic Plan 2015-2040: Grow Bold set out a new framework for economic growth and city building in Burlington with a focus on making Burlington a thriving and innovative entrepreneurial hub. As part of the implementation of Grow Bold Burlington Economic Development Corporation (BEDC) was tasked to "Create and invest in a system that supports the startup and growth of businesses and entrepreneurship."

Traditionally BEDC's business model was focused on the attraction and retention of mid to large businesses rather than supporting the startup and scale-up of new businesses. Small business support was provided by the Halton Region Small Business Enterprise Centre located in the municipality of Oakville. The implementation of an Innovation and Entrepreneurship Strategy in Burlington required a shift in the business model of BEDC and the development of the necessary knowledge base and skill sets to support this new direction while complimenting, not duplicating existing services.

To develop an Innovation and Entrepreneurship Strategy BEDC undertook an extensive research process which included the following key elements:

- Ecosystem and Asset Mapping

- Stakeholder Engagement

- Research and Data Analysis

- Best in Class and Next Practice Analysis 


\section{Developing Burlington's new innovation and entrepreneurship strategy}

Understanding the economic impact of entrepreneurship

According to the Organization for Economic Cooperation and Development (OECD), entrepreneurship is defined as, "enterprising human action in pursuit of the generation of value, through the creation or expansion of economic activity, by identifying and exploiting new products, processes or markets" (Ahmad and Hoffman, 2007). It is a powerful force in driving job creation, economic growth, productivity and innovation (Industry Canada, 2010). The Kauffman Foundation in a study of job creation and destruction found that "without startups, there would be no net job growth in the US Economy" (Kane and Marion, 2010) and an OECD study on the effects of firm age and size on job creation across 18 different countries including Canada came to a similar conclusion with on average small young firms contributing to over $40 \%$ of job creation in Canada (Criscuolo, Gal, and Menon, 2014).

Even considering the failure rate, high risk environment and job destruction rates of young firms; job creation rate of young firms in Canada experienced a net employment growth rate over 10\% while old firms exhibited a negative growth employment rate from 2001-2011 (Criscuolo, Gal, and Menon, 2014). It is clear from this evidence that entrepreneurship and startups are of critical importance in job creation and economic growth.

However, not all entrepreneurs have the desire or potential to grow and scale their business. Entrepreneurs can be split into three broad categories:

- Small Business or Main Street Entrepreneurs: These businesses serve a local community function with limited scalability or desire to scale. They are typically led by entrepreneurs running the business to meet their personal and family needs. These businesses can operate across all sectors from retail to manufacturing facilities.

- Scalable Startups or High Growth Potential Entrepreneurs: These businesses have a larger market potential with the ability to scale up. They are typically led by entrepreneurs who have an interest in building equity in a larger business rather than looking for the short-term return of a salary. These startups are looking to significantly grow or scale up their business and have a growth orientation and high growth potential.

- Nonprofit or Social Entrepreneurs: These businesses focus on addressing a social need. They run the business because they are passionate about reaching their social goals and may have similar revenue and growth potential to scalable startups depending upon their business model and the scale of the social need they are addressing (Kauffman Foundation, 2011).

The scalable and high growth potential startups represent the largest potential for job creation and economic impact creation; these firms have high rate job creation and disproportionately contribute to private sector job creation (Kauffman Foundation, 2013). However, young firms and startups face high risks and barriers to growth and scale up. This is particularly true as they 
develop and test their business model. Not every business idea will be viable represented by the high failure rate and job destruction rates of young firms. Driving job creation through entrepreneurship and scaling up high growth companies requires a supportive environment to create a large base of startups to draw from.

\section{Innovation and entrepreneurship best practice and next practice}

\section{The innovation \& entrepreneurship ecosystem}

To better understand what allows entrepreneurship to flourish and generate economic benefits we must consider the many factors that create successful startups and the culture that supports them. Entrepreneurial success does not come from a single organization or policy: it comes from a complex ecosystem of organizations, policy and culture which together form an ecosystem that supports entrepreneurship. This Entrepreneurship Ecosystem is dynamic and is affected by a number of factors. A good high-level model to understand the complexity and underlying components of this ecosystem is the 'Entrepreneurship Ecosystem Strategy for Economic Development' (Isenberg, 2015). This model identifies several complex components that interact together to influence the health and success of the entrepreneurial ecosystem (Isenberg, 2015). The model identifies six domains within the ecosystem: a conducive culture, enabling policies and leadership, availability of appropriate finance, quality human capital, venture-friendly markets for products, and a range of institutional supports (2015). These institutions, policies and private sector actors come together in complex ways to form a successful entrepreneurial ecosystem.

In order to understand how such a complex ecosystem operates in practice and how we can hope to understand and influence such a complex set of factors, BEDC undertook interviews with a broad range of stakeholders in best in class entrepreneurial ecosystems. Combining the insights from these interviews with the practical insights provided in Start-Up Communities (Feld, 2012), Brad Feld's model of the entrepreneurial ecosystem of Boulder, Colorado BEDC arrived at a simplified model of eight key areas that make up a successful ecosystem and that can be influenced by organizations working at the city and regional level.

\section{Entrepreneurial leadership and celebrating entrepreneurship}

Entrepreneurial leadership and engagement are at the heart of any successful entrepreneurial ecosystem (Feld, 2014). Looking at the many examples of best in class ecosystems from the Kitchener/Waterloo region to the development of Boulder, Colorado there is strong leadership by successful serial entrepreneurs. These serial entrepreneurs have gained the experience of building and selling a successful company. They may not always be successful but they know the importance of failing fast and taking the lessons they have learned and applying them in the entrepreneurial ecosystem. They move on to found a new business, take a position in another startup, invest in other businesses, mentor other businesses both formally and informally and 
share their story with the community. The experience they gain and the conscious decision to support others in the community helps build a network of experienced entrepreneurs who are invested in the long-term success of the community.

\section{Large companies \& mentorship}

While investors and experienced entrepreneurs support the development of startups providing mentorship based on their practical experience, the support of large companies is also essential in several ways. Large companies act as a critical source of mentorship, technical expertise, a talent base, and attract and support startups as part of their supply chain. As large companies become more engaged in the entrepreneurial ecosystem, they reinforce entrepreneurial culture with their employees who are encouraged and motivated through the successful commercialization of their colleagues' ideas that resulted in successful startups. This, in turn, decreases an employee's perceived risk of entrepreneurship making it more accessible. These spinoff effects were seen in the entrepreneurial ecosystems in Austin, Texas and Boulder, Colorado (Neck et al, 2004).

\section{Capital}

From interviews with best in class ecosystems access to capital emerged as critical at every stage of the startup and scale up of companies. Successful ecosystems allow market forces to operate by allowing startups with a scalable business model to be self-selected by first boot strapping then moving on to angel investors, venture capital investors (VCs) and traditional financing institutions as their business model develops and becomes validated by the market. In successful entrepreneurial ecosystems experienced investors and angels make the bets on who will be the high growth companies through both traditional financing, mentorship and for-profit accelerator models. Some examples of these accelerator models include 500 Startups, Techstars and $Y$ Combinator; these models typically select companies for investment in cohorts and bring them on site for a boot camp style program typically lasting 8-12 weeks.

\section{Talent}

The input of expertise and knowledge from both founders with new ideas, to technical talent to business skills is essential to the growth of a successful entrepreneurial ecosystem. There is a steady stream of new entrepreneurial talent coming into the ecosystem locally and the ecosystem becomes a magnet for new entrepreneurial talent by building a reputation as a supportive environment for startups. The internal talent comes from serial entrepreneurs, spin off from large companies and universities. In addition to entrepreneurial talent there needs to be a ready supply of those with technical talent (such as engineering, programmers, researchers, etc.) and business skill sets that support business model development, business growth and/or scaling up. 


\section{Research institutions}

Post-secondary institutions are an integral component of entrepreneurial ecosystems as they often can create a pipeline of talent and ideas. They are key to the development of a strong entrepreneurial ecosystem through a combination of commercialization support for staff and students, the development of entrepreneurial programs for students, the launch and management of incubators and accelerators and the ongoing engagement of alumni who financially support the ecosystem through institutional and community endowments.

In addition to post-secondary research institutions, public and private research labs have played a critical role in the idea production, commercialization and spin off of companies as well as attracting talent to the region. An example of this in practice that was cited by many stakeholders interviewed is the Ottawa ecosystem where the Federal Government R\&D labs and Bell Northern Research (later Nortel) generated many high growth spinout companies. The most high profile example is Mitel founded by Sir Terry Matthews and Michael Copland. Matthews and Copland met while working at Nortel and went on to sell Mitel that led to the creation of many subsequent ventures.

\section{Commercialization support}

To turn an idea into a viable product entrepreneurs need a support creating a business model that addresses a need within a target market. . Best in class ecosystems have a variety of mechanisms to help the entrepreneur along this path from the back-of-the- napkin-idea to pitching to investors to growing and scaling their business. The types of organizational and service supports vary based on where entrepreneurs are in their startup journey (Startup Commons, 2015).

\section{Network density and engagement}

Successful entrepreneurial ecosystems are characterized by a high degree of connectivity between entrepreneurs, companies, mentors, investors, and support organizations (Feld, 2014). These connections can be both formal and informal, visible and invisible. At the visible end of the spectrum, these ecosystems are highly connected through open public events that connect participants in the ecosystem. These can take the form of meetups, pitch competitions, networking events and entrepreneurial celebrations. They are typically free and are not run by any one organization or person but by a number of entrepreneurs and support organizations adding vibrancy and diversity to the startup ecosystem.

According to interviews with best in class ecosystems not only do successful ecosystems provide a focal point to the entrepreneurial community through events and space, it also has a highly connected network of support organizations working to help grow startups. These can range 
from early stage startup support - typically offered by post-secondary institutions, government organizations and not-for-profits - to a solid network of business services that includes law firms, accountants and consultants. These businesses service the unique needs of new companies helping them navigate the complicated issues from how to structure their company as a legal entity to ensure a new startup has a solid intellectual property (IP) base to build upon. The individuals and organizations with the support ecosystem are well connected providing a clear path and while building mutually beneficial relationships with partners to support the long-term growth of the ecosystem.

\section{Burlington's innovation ecosystem}

The work BEDC undertook in the study of successful innovation ecosystems identified the key elements that we see in these ecosystems. However, each ecosystem is unique and plays to its own strengths and weaknesses. The following section outlines the key strengths, weaknesses, opportunities and threats in Burlington's Innovation Ecosystem. This is based on the analysis undertaken in 2016 comparing the common traits of successful ecosystems and applying them using Burlington's unique assets and attributes. The Burlington regional Ecosystem has many existing organizations that service the entrepreneurial community shown in Figure 8.

Figure 8. Burlington's entrepreneurial support organizations



Entrepreneurial ecosystem SWOT

To help arrive at a full understanding of Burlington's ecosystem, BEDC met with each of the partners shown in Figure 8 to understand their perception of the ecosystem. This research formed the basis of the SWOT analysis. 


\section{Strengths}

Access to capital

Burlington and Halton Region have a strong base of investors and capital to support the development and scale-up of startups. The largest group regionally is the Angel One Investors Network located in Burlington. This network is comprised of more than 100 accredited investors who have invested $\$ 44$ Million in 76 deals over the last five years. Also, due to Burlington and the Region's above average affluence there could be potential for an additional source of investment to foster growth of local startups. Furthermore, because of Burlington's proximity to Toronto there is the ability to tap into Toronto based venture capital firms and investment opportunities. There is a significant opportunity to increase both the profile of angel investing in the community and position Burlington as a destination for those early stage companies looking for startup capital and angel investment.

\section{Mentorship}

Partners across Halton region, as well as other ecosystems, identified two key ingredients for the growth and success of startups. First, a strong mentorship network that includes highly successful individuals and community leaders. The second key ingredient identified was the support of the innovation ecosystem by established companies. Burlington is well positioned with its well established base of mentorship and community volunteerism; these are already being leveraged by organizations like HalTech and FreshInsights. Opportunities exist to both leverage the experience of community-minded business leaders for both mentorship and startup support and, as a result, will lead to a stronger connectivity between Burlington's established companies and the innovation ecosystem.

\section{Partnerships with post-secondary institutions}

Burlington is well positioned being at the center of several world class research institutions, or as BEDC has termed it the 'Brain Triangle'. BEDC has already established strong partnerships with McMaster University and Mohawk College and is in the process of creating a partnership with Sheridan College. Burlington's post-secondary institutions are an essential component to Burlington's innovation ecosystem providing both ideas for commercialization and young entrepreneurs and talent to the ecosystem. There are opportunities to develop collaborative programming particularly around developing and supplying business skills and support to startups. This is a recognized gap for early stage companies looking to develop a successful business model and build sales.

\section{$\underline{\text { Weaknesses }}$}

Entrepreneurial leadership and promotion 
In Burlington and Halton Region the many events and activities supporting entrepreneurship and innovation are led by government agencies such as Haltech except for Silicon Halton. Silicon Halton an organization of over 1,000 members that run regular meet-ups across Halton connecting like-minded entrepreneurs.

Although Burlington has many highly successful companies and business leaders in the community, most members and leaders in the innovation ecosystem are solopreneurs, entrepreneurs who typically work alone or engage contractors, and lifestyle entrepreneurs, whose objective is to support their lifestyle rather than generate profits and create a scalable business model. Regionally there is a need to encourage successful serial entrepreneurs to have greater involvement in the local startup scene through leadership roles while increasing the number of events and meetups taking place in the community. This would help to better connect entrepreneurs, increase the vibrancy of the startup scene and build Burlington's reputation as a startup destination.

\section{Coordination \& connectivity}

A common theme heard from both local partners and entrepreneurs as well as 'best in class' organizations was the need for partners to be highly coordinated and closely connected in both service delivery and in supporting the innovation ecosystem. Of all the successful innovation ecosystems examined, there was a concentration of partners through either co-location (or in close proximity) in addition to a clear understanding of each partner's role in supporting startups. Cross promotion and referrals of clients between partners were cited as important contributors to ecosystem success.

Currently, Halton Region's services are lacking in connectivity and proximity. There is also a lack of clear direction of how or where to access support services. Creating a space where partners could co-locate along with the inclusion of collision space would be a first step in creating greater synergy between partners while offering startups and high growth firms a clear destination for support services.

\section{Talent pool}

A key weakness for Burlington to generate and sustain an innovation ecosystem is the lack of affordable housing and office space for youth and early stage companies. In Hamilton, there is a significantly lower cost of living, office and industrial rental rates and it offers several coworking and incubator spaces. Despite the lack of available supportive space for entrepreneurs Burlington does have a strong base of highly qualified and experienced professionals as well as many established companies that are interested in connecting with and supporting early stage companies. Taking a more regional and coordinated approach to generate a regional innovation ecosystem inclusive of Hamilton, could potentially lead to the development of a more robust, mutually beneficial talent base. There needs to be a coordinated effort with Hamilton across a 
range of issues to support the long-term robustness of a regional talent base that can support the growth of startups and high growth firms across both the Hamilton and Halton regions.

\section{Burlington's innovation and entrepreneurship strategy: Recommendations}

Based on the analysis, a key underlying principle of BEDC's support the growth of Innovation and Entrepreneurship is the understanding that government, and more specifically BEDC, should not be the leader of the innovation ecosystem in the region. The innovation ecosystem should be entrepreneur and community led, this will ensure long-term success through the creation of a robust and vibrant startup scene.

Startup communities are successful because of the people who participate in them, the spaces that bring them together, and the availability to capital. Therefore, BEDC chose to focus on supporting the startup community in three key areas:

- Space \& energy - Through providing space and a place for entrepreneurs and support agencies to come together BEDC could foster greater opportunities for networking, storytelling, and idea sharing across the region.

- Mentorship \& support - BEDC should help make it as easy as possible for local innovators and creators to tap into resources, peers, and mentors for guidance.

Developing programming and partnership opportunities to bring in investors, established business leaders, and community influencers into the entrepreneurial ecosystem.

- Capital \& growth - BEDC should support local service providers in preparing young companies for investment, as well as help attract new sources of capital to the community through space, partnerships, and promotion.

To help build support for all these elements BEDC staff recommended to their Board in October 2016 the focus of the Innovation \& Entrepreneurship Strategy should be the development of an Innovation Centre in Burlington.

Key benefits from the creation of an Innovation Centre would include:

- Creating a one stop destination for starting up and growing businesses

- Creating entrepreneurial Collision Space and increased entrepreneurial vibrancy

- Increasing the visibility of entrepreneurship and brand recognition of Burlington as a Startup Community

- Expanding entrepreneurship programming and support

- Connecting large companies and investors to the entrepreneurial ecosystem

- Increasing entrepreneurial and community leadership

- Providing the ability to measure the growth of entrepreneurial activity

The key elements delivered through the Innovation Centre would include:

- Co-location of support services: The Centre could bring together key partners in the innovation ecosystem through hosted office space and programming. 
- Programming and events: Events and meetups would take place at the Centre focused on providing entrepreneurial support.

- Scale up space: Providing small private office space for companies scaling up. These companies would be at a stage in their growth where they require private office space but are not yet at a large enough scale to be able to support a commercial lease.

- Company launch pad: Providing external companies looking at expansion or relocation in Burlington with a launch pad space at the Centre to begin conducting business operations and get a better feel for the local business community and services.

- Incubators and Accelerators: To provide the development of scale up support partnerships with service providers to locate both not-for-profit and for-profit incubators and accelerators in Burlington. For qualifying companies, they would provide more intensive support to help grow their business and validate their business model.

\section{Conclusion}

Through stakeholder engagement, research and best practice analysis BEDC was able to move from no competency to support startup and scaling of companies to addressing a key gap in Burlington's entrepreneurial ecosystem. The result was the creation of a space for companies, entrepreneurs, mentors and service providers to connect and grow. TechPlace, Burlington's new Innovation Centre, launched in June 2017 bringing together support services, colocation partners, programming, events, and launch pad space. Providing over 8,600 square feet of space in a one stop destination for companies starting up and scaling up. TechPlace has exceeded all expectations in year one of operations; it has supported over 4,000 visitors, hosted over eighty events to support companies to start up and scale up, as well as welcoming seven new companies to Burlington and supporting them to scale up their operations.

\section{Author Biography}

Anita Cassidy is an accomplished leader responsible for the strategic direction and management of Burlington Economic Development Corporation (BEDC). Leading a team that supports companies to locate, start and grow in Burlington, Ontario. Attracting and growing over 1,000 jobs and \$100 Million in ICI (Industrial, Commercial, and Institutional) assessment value per year for Burlington. Anita has worked for BEDC since immigrating to Canada from Europe. A graduate of the University of Glasgow with a B.Sc. in Earth Science, M.A. Sociology \& History and an M.Sc. in Economic Development. Anita blends the perspectives of an extensive background in European and North American economic development practices to deliver unique strategies to support the growth of Burlington. 


\section{References}

Ahmad, N. and Hoffman, A. (2007). A Framework for Addressing and Measuring Entrepreneurship. OECD Statistics Working Papers. http://www.oecd.org/industry/businessstats/39629644.pdf.

Isenberg, D., (2015). Babson Entrepreneurial Ecosystem Project. Retrieved from http://entrepreneurial-revolution.com/lessons/

Blank, S. (2011). Kauffman Foundation: Typecasting the Entrepreneur.. Accessed July 20, 2016. http://www.kauffman.org/what-we-do/articles/2013/06/typecastingthe-entrepreneur.

City of Burlington. Burlington's Strategic Plan 2015 - 2040: Grow Bold. (2015). Retrieved from https://www.burlington.ca/en/services-foryou/resources/Ongoing_City_Projects/Strategic_Plan/Burlingtons-Strategic-Plan-Draft-forConsultation-Web.pdf.

Criscuolo, C., Gal, P and Menon, C. (2014). The Dynamics of Employment Growth: New Evidence from 18 Countries. OECD Science, Technology and Industry Policy Papers, No. 14.

Feld, B. (2014). Startup Communities: Building an Entrepreneurial Ecosystem in Your City. United States: Wiley, John \& Sons.

Haltiwanger, J. C., Hyatt, H. R., McEntarfer, E., and Sousa, L. D. (2012). Business Dynamics Statistics Briefing: Job Creation, Worker Churning, and Wages at Young Businesses. Kauffman Foundation. https://www.census.gov/ces/pdf/BDS_StatBrief7_Creation_Churning_Wages.pdf.

Neck, H. M., Meyer, G. D., and Cohen, B. (2004). An Entrepreneurial System View of New Venture Creation. Journal of Small Business Management. 42(2).

Industry Canada. (2010). The State of Entrepreneurship in Canada. Retrieved from https://www.ic.gc.ca/eic/site/061.nsf/vwapj/SEC-EEC_eng.pdf/\$file/SEC-EEC_eng.pdf.

Kane, T and Ewing, M. (2010). The Importance of Startups in Job Creation and Job Destruction. Retrieved from http://www.kauffman.org/ /media/kauffman org/research\%20reports\%20and\%20covers/2010/0 7/firm_formation_importance_of_startups.pdf.

Kauffman Foundation. (2013). Retrieved from http://www.kauffman.org/ /media/kauffman_org/research\%20reports\%20and\%20covers/2013/0 8/bdstechstartsreport.pdf. 
Langford, C. H., Josty, P., and Saunders, C. (2016). Global Entrepreneurship Monitor (GEM) Canada Report. Retrieved from http://thecis.ca/wp-content/uploads/2016/04/GEM-CanadaReport-5.2015.pdf.

Mason, C., and Brown, R. (2014). Entrepreneurial Ecosystems and Growth Oriented Entrepreneurship. OECD LEED Programme. Retrieved from http://www.oecd.org/cfe/leed/entrepreneurial-ecosystems.pdf.

Millier Dickinson Blais. (2015) Burlington Economic Vision 2025: Final Report. Retrieved from http://bedc.ca/wp-content/uploads/2015/09/DRAFT-Economic-Vision-Directions-Report-June2015.pdf.

Neck, H. M., Meyer, D. G., Cohen, B., and Corbett, A., C. (2016). An Entrepreneurial System View of New Venture Creation. Journal of Small Business Management. 42(2)

Ontario Chamber of Commerce. (2016). Breaking Barriers: Ontario’s Scale Up Challenge. Retrieved from http://www.occ.ca/wp-content/uploads/2013/05/Breaking-Barriers-OntariosScale-Up-Challenge.pdf.

Parsley, C., and Halabisky. D. (2008). Profile of Growth Firms: A Summary of Industry Canada Research. Retrieved from http://www.ic.gc.ca/eic/site/sbrp-rppe.nsf/eng/h_rd02278.html.

Science, Technology and Innovation Council. State of the Nation 2014: Canada's Science, Technology and Innovation System. (2015). Retrieved from http://www.stic-csti.ca/eic/site/sticcsti.nsf/vwapj/STIC_1500_SON_Report_e_proof4.pdf/\$file/STIC_1500_SON_Report_e_proof4 .pdf

Startup Commons. (2015). Retrieved from https://www.startupcommons.org/startup-key-stagesprevious-versions.html

Statistics Canada. (2015). Entrepreneurship Indicators Database. Retrieved from http://www23.statcan.gc.ca/imdb/p2SV.pl?Function=getSurvey\&SDDS=5157\&lang=en \&db=im $\mathrm{db} \& \mathrm{adm}=8 \& \mathrm{dis}=2$ 